\title{
High-Throughput Phenomic Characterization of Wheat Grain Architecture and Diversity for Conventional Morpho-Physiological Traits
}

\author{
Shafiq-Ur-Rehman*, Sardar Ali Khan, Shahid Iqbal Awan and Muhammad Ilyas \\ Department of Plant Breeding and Molecular Genetics, Faculty of Agriculture, University of Poonch Rawalakot, Azad \\ Kashmir \\ *For correspondence: shafiqurrehman@upr.edu.pk
}

Received 28 October 2020; Accepted 22 February 2021; Published 16 April 2021

\begin{abstract}
Grain morphology affects the weight of grain which ultimately affects grain yield in wheat. Several morpho-physiological traits influence grain morphology. To assess the diversity for morpho-physiological traits and to characterize wheat for grain morphology, a collection comprising of 60 wheat varieties were explored. The ANOVA showed significant differences between varieties for all the parameters except grain thickness, peduncle length, and plant height. Descriptive statistics indicated that the collection of germplasm contained enough variability for the traits under consideration. Grain architectural traits showed positive significant correlations with most of the metric traits suggesting several criteria for indirect selection of traits like grain yield. A positive significant correlation of WUE was observed with grain morphology traits viz: grain width, grain size, grain thickness and grain volume. While 1000 grain weight, water use efficiency, grain length, grain width, grain size, grain thickness and grain volume showed positive significant correlation with grain yield. Principal component analysis extracted seven significant PCs having a cumulative variance of $78.87 \%$. This variation was quite encouraging to initiate a breeding program to improve grain morphology and morpho-physiological traits. The PC1 indicted that grain width, unproductive water use, grain area size, and grain volume were the most diverse traits. In PC2, the maximum positive contribution towards variation was shown by the grain area, grain length and grain volume. The cluster analysis grouped varieties into seven clusters of high, medium, and low performance based on morphology and grain architecture traits. This classification might help in the selection of high and low performing varieties and could be used as parents in hybridization program. (C) 2021 Friends Science Publishers
\end{abstract}

Keywords: Genepool; Grain Morphology; Varieties; Wheat; WUE

\section{Introduction}

Morphological features like grain volume and shape in wheat have profound effects on grain weight and flour yield (Williams et al. 2013). Improvement in these traits is the main objective of plant breeders from marketing point of view (Gegas et al. 2010). The milling yield could be improved by modifying grain morphology (Evers et al. 1990). A significant positive relationship has been observed in grain size and milling yield. This relationship is quite variable among the genotypes indicating scope for the improvement through selection. The density of seed also influences the milling yield. The crease of seed is critical in milling quality and mechanical work. It is considered as cleavage point of wheat grain. The size and depth of crease is also important for breeders. Grain size depends on the factors like test weight, size of the embryo, grain crosssection and smooth surface area (Marshall et al. 1986).

The grain size, shape and color variation have economic implications in bread wheat. These are the primary physical features that determine the market value of grain (Tańska et al. 2018). The grain size is positively correlated with specific grain weight, a trait related to the efficiency of wheat transport and storage of photosynthates (Clarke et al. 2004). A high proportion of small grains is commercially disliked by the milling industry because the small grains are lost during the cleaning process prior to milling. In addition, a high percentage of small grains are indicative of a poor flour yield (Nuttall et al. 2017). The digital system is a useful tool for capturing 3-D analysis of grains image dimensions. Phenomic characterization through digital imaging (DI) can capture the threedimensional variation in wheat grain size and shape using different image orientations (Ali et al. 2020).

From agronomic perspectives, wheat grain yield is the most important trait. Grain yield in bread wheat is usually analyzed through various yield components: the number of spikes $\mathrm{m}^{-2}$, the number of grains spike $^{-1}$, the number of grains $\mathrm{m}^{-2}$ and the thousand-kernel weight (TKW) (Ahmad et al. 2019). Correlation of yield traits with morpho-

To cite this paper: Shafiq-Ur-Rehman, SA Khan, SI Awan, M Ilyas (2021). High-throughput phenomic characterization of wheat grain architecture and diversity for conventional morpho-physiological traits. Intl J Agric Biol 25:1131-1139 
physiological traits has been reported for efficient selection in wheat. Strong negative relationship between these yield components have already been found for both environmental and genetic sources of variation between (i) the number of spikes $\mathrm{m}^{-2}$ and the number of grains spike and (ii) the number of grains $\mathrm{m}^{-2}$ and 1000 grains weight (Beral et al. 2020). Improvement in grain weight is considered a promising approach to improve wheat yield potential and is regarded as an important area of wheat genetic and breeding studies. Similarly, water use efficiency and the dry matter are related to volume of wheat grain. If water content is high during grain formation, the seed volume will also be increased. The water use enhances the values of all seed parameters which increases crop yield. An increase in length, width, thickness, and volume indicates that there is more space for photosynthates during the grain filling period (Hasan et al. 2011).

Knowledge of genetic diversity for grain morphology and water use efficiency found in the Pakistani wheat varieties is still incomplete. Keeping in view the importance of cited issue, the present research was conducted with the objective to determine the intra-cultivar variation of image features for grain shape, size and to determine its association with grain weight using high-throughput digital imaging phenotyping and to assess the diversity among wheat varieties for traits like grain morphology, WUE and grain yield.

\section{Materials and Methods}

This research work was conducted at the Department of Plant Breeding and Molecular Genetics, Faculty of Agriculture, University of Poonch Rawalakot, Azad Kashmir. The seed material included sixty hexaploid spring wheat varieties were acquired from National Agriculture Research Center (NARC) Islamabad, Pakistan (Table 1). The seed of each variety were sown in 02 rows during Rabi seasons of 2014-2015 and 2015-2016 in an augmented block design with three blocks. The check varieties i.e., NARC-2009, NARC-2011 and Ufaq-2002 were replicated after every 20 entries. The row to row spacing was kept 30 $\mathrm{cm}$. The row length was kept $3 \mathrm{~m}$ long.

\section{Data collection}

The data were collected from ten plants for parameters namely, flag leaf area $\left(\mathrm{cm}^{2}\right)$, number of tillers plant ${ }^{-1}$, peduncle length $(\mathrm{cm})$, number of spikelets spike $^{-1}, 1000$ grain weight $(\mathrm{g})$ and grain yield plant ${ }^{-1}$. The physiological traits included water use (WU), water use efficiency (WUE), potential yield $\left(\mathrm{kg} \mathrm{ha}^{-1}\right)$, percentage of potential yield achieved, transpiration and unproductive water-use. The summer fallow and growing season rainfall data were acquired from Pakistan Meteorological Department (http://www.pmd.gov.pk) and the water use was calculated by assuming that $25 \%$ of rainfall received during the summer fallow is stored for crop use (Hunt and Kirkegaard 2013). It also assumes that there is no water carrying over from the previous season. It was calculated by using the formula:

Water use $=0.25 \times$ (summer fallow rainfall + growing season rainfall $)$

Water use efficiency was estimated by dividing grain yield with water use. The potential yield was estimated by following French and Schultz (1984).

$$
\text { Potential yield }(\mathrm{kg} / \mathrm{ha})=22 \times \text { (wateruse }-60)
$$

The percentage of potential yield achieved was obtained as a ratio of actual crop yield to potential yield, while the transpiration was estimated by the following farmula:

Transpiration $(\mathrm{mm})=\frac{\text { total dry matter }(\mathrm{kg} / \mathrm{ha})}{55}$

The unproductive water-use was obtained by computing the difference between water-use and transpiration (Hunt and Kirkegaard 2013).

\section{Phenotyping for grain morphology}

Phenotyping based on digital imaging (DI) of grain size and various orientations was conducted as proposed by Rasheed et al. (2014). Twenty-five grains were photographed with the help of a digital camera (Sony Alpha NEX5 digital). A sample of sound and healthy seeds of the varieties was selected by visual observations. To provide color contrast seeds were placed in a horizontal and vertical position with equal distances (Fig. 1). Two photographs were taken from each unit. After assigning names all images were cropped using Adobe Photoshop (www.adobe.com/products/photoshop). Image contrast and brightness were also improved to minimize the edge detection error.

\section{Grain analysis}

Smart Grain Software (www.nias.affrc.go.jp/qt//SmartGrain/) is developed for high-throughput measurement of seed shape. This software uses a new image analysis method to minimize the time taken in the preparation of seeds and image capture. Outlines of seeds are automatically recognized from digital images. Several shape parameters, such as grain length, grain width, grain size, grain thickness, and grain volume were calculated. High-throughput measurements with Smart Grain lessen the sampling error and made it possible to distinguish between lines with small differences in seed shape. Smart Grains Software can accurately recognize grains of wheat (Rasheed et al. 2014). Twenty-five healthy grains were selected for pictorial representation. Horizontal and vertical images of wheat grains were taken (Fig. 1). For horizontal image, the grains were placed at equidistance while their germ ends were pointing to the same side and crease of the grains was facing downward direction. For vertical image, the brushy 
Variation in Grain Morphology using Digital Imaging / Intl J Agric Biol, Vol 25, No 5, 2021

Table 1: Wheat varieties utilized to screen water-.use efficiency, grain morphology, grain yield and yield related traits

\begin{tabular}{llllllll}
\hline Sr. No & Varieties & Sr. No & Varieties & Sr. No & Varieties & Sr. No & Varieties \\
\hline 1 & Kohistan-97 & 16 & Pavon-76 & 31 & Johar & 46 & Tatara \\
2 & Noshehra-96 & 17 & Zardana & 32 & Janbaz & 47 & NIA-Amber \\
3 & Parwaz-94 & 18 & Paster & 33 & AARI & 48 & NARC-2009 \\
4 & Kiran-95 & 19 & PBW-373 & 34 & Anmol-91 & 49 & Takbeer \\
5 & Fakhar-e-Sarhad & 20 & Manthar-03 & 35 & NIA-Sunari & 50 & Ufaq-2002 \\
6 & Suleman-96 & 21 & MH-97 & 36 & Pasban-90 & 51 & NIFA Barsat-09 \\
7 & Khayber-87 & 22 & Blue Silver & 37 & Zam-04 & 52 & Millet-2011 \\
8 & Saleem-2000 & 23 & Marvi-2000 & 38 & Nasir-2k & 53 & Pirsabak-2013 \\
9 & Yacora-70 & 24 & Bahwalpur-97 & 39 & Imdad-1 & 54 & KT-2000 \\
10 & Bhitai & 25 & Pirsabaq-2005 & 40 & Tijbans & 55 & SKD-1 \\
11 & Chakwal-97 & 26 & SH-2002 & 41 & Darabi-2011 & 56 & Gomal-08 \\
12 & Margalla-99 & 27 & Punjab-85 & 42 & Tandojam & 57 & Pirsabak-2008 \\
13 & Fareed-2006 & 28 & Kaghan-93 & 43 & Shaheen-94 & 58 & TD-1 \\
14 & Bakhtawar-93 & 29 & Moomal-2002 & 44 & Benezir & 59 & Pak-81 \\
15 & Mehran-87 & 30 & Abadgar-93 & 45 & NARC-2011 & 60 & Sarsabz \\
\hline
\end{tabular}

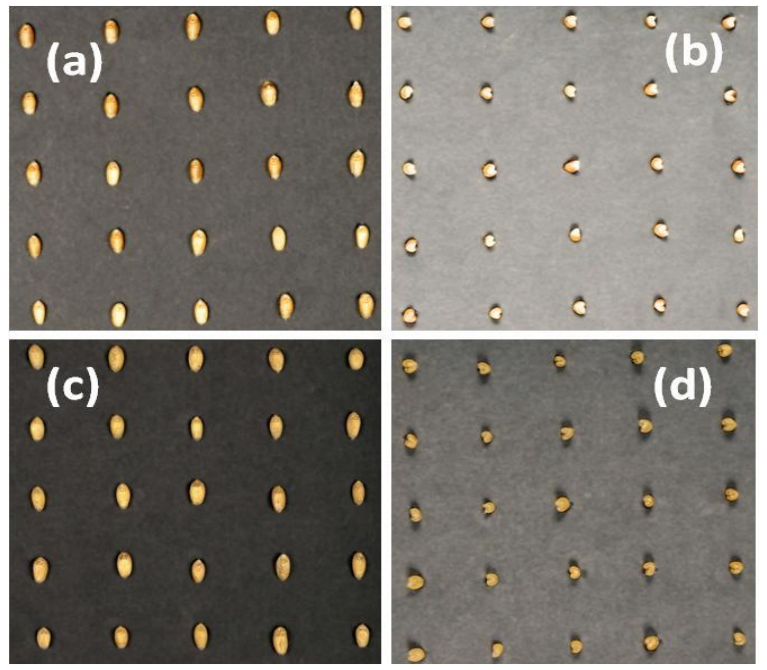

Fig. 1: Horizontal and vertical grain arrangements for digital imaging in varieties Manthar-03 (a \& b) and Gomal-08 (c \& d)

ends were facing upwards direction and germ ends were facing downward direction. The digital images were analyzed by the software "Smart Grain". The parameters like grain length, width, grain area size and perimeter length were obtained. The images were selected for the measurements, and then seed color and background color were selected to measure the parameters. From horizontal images length, width, and grain area size of 25 grains were obtained. For vertical images, the length of the seeds was considered the thickness of the grain. It gave the average values of parameters for each variety. Horizontal area and vertical thickness provided the volume of the grains. Smart Grain provided values for the parameters like grain width, grain size, grain volume, and grain thickness.

\section{Statistical Analysis}

Analysis of variance was done by using the software AgriSTAT. Pearson's correlation coefficients between morphophysiological and grain architecture traits were assessed following the method previously reported by Snedecor
(1956). Principal component (PCA) and cluster analyses were used to assess the diversity among wheat varieties for the grain yield and related parameters, water use efficiency and grain morphology. As scales of measurement of different traits were different therefore, the means were standardized as Hair et al. (2006), followed by the construction of dendrogram utilizing Ward's method (Kumar et al. 2009) using software Past Ver. 3 (Hammer et al. 2001). All measurements regarding the assessment of grain morphology were recorded by using Smart Grain package v. 1.3 (http://phenotyping.image.coocan.jp).

\section{Results}

\section{Analysis of variance and correlation}

Analysis of variance showed non-significant differences among varieties for grain thickness, peduncle length, and plant height (Table 2). To analyze whether grain morphology was linked to average yield components, Pearson's correlations were calculated between grain characters and each yield component (Table 3). The traits viz., flag leaf area, plant height, number of tillers per plant, spike length, number of spikelets spike ${ }^{-1}$, biological yield, 1000 grain weight, water use efficiency, grain width, grain size, grain thickness and grain volume showed positive significant correlation with grain yield. A positive significant correlation of WUE was observed with grain morphology traits viz., grain width, grain size, grain thickness and grain volume. In general, the grain morphology showed positive significant correlations with most of the morpho-physiological traits, showing multiple directional models for the selection of complex traits. By using grain characters that are easy to assay and simple to score, a broad range of complex traits can be selected indirectly.

\section{Principal Component Analysis}

The PCs with Eigen value greater than Joliffe's cut off value of 0.75 were considered significant. Seven significant 
Shafiq-Ur-Rehman et al. / Intl J Agric Biol, Vol 25, No 5, 2021

Table 2: Mean squares for morpho-physiological and grain architecture traits in 60 spring wheat varieties

\begin{tabular}{|c|c|c|c|c|c|}
\hline Source & Blocks & Varieties & Checks & Test Entries & Check x Test \\
\hline Df & 2 & 59 & 2 & 56 & 112 \\
\hline FLA & $1.92 * *$ & $14.85 * *$ & $41.66^{* * *}$ & $13.77 * *$ & $22.89^{* *}$ \\
\hline PH & $12.79^{\mathrm{NS}}$ & $7.06^{\mathrm{NS}}$ & $13.7^{\mathrm{NS}}$ & $7.13^{\mathrm{NS}}$ & $4.3^{\mathrm{NS}}$ \\
\hline NOT & $0.68^{*}$ & $1.08 * *$ & $2.65 * *$ & $1.02 * *$ & $1.14^{*}$ \\
\hline SL & $0.44 * *$ & $0.72 * *$ & $7.34 * *$ & $0.49 * *$ & $0.54 * *$ \\
\hline PL & $0.05^{\mathrm{NS}}$ & $1.05^{\mathrm{NS}}$ & $0.09^{\mathrm{NS}}$ & $1.10^{\mathrm{NS}}$ & $0.06 \mathrm{NS}$ \\
\hline NSL & $4.70 * *$ & $3.58 * *$ & $3.56^{* *}$ & $3.79 * *$ & $8.42 * *$ \\
\hline BY & $4542743.29^{*}$ & $3324562.54^{\mathrm{NS}}$ & $6312872.56^{*}$ & $3280638.12 *$ & $148365.91^{\text {NS }}$ \\
\hline GY & $360360 * *$ & $132308 * *$ & $84266^{* *}$ & $144981 * *$ & $494009 * *$ \\
\hline $1000 \mathrm{GW}$ & $4.89 * *$ & $32.60 * *$ & $86.04 * *$ & $31.32 * *$ & $1.41^{\mathrm{NS}}$ \\
\hline WUE & $0.39 * *$ & $0.12 *$ & $0.11^{*}$ & $0.13^{*}$ & $0.64 * *$ \\
\hline$\%$ of PY & $38.32^{*}$ & $11.21^{\mathrm{NS}}$ & $9.14^{\mathrm{NS}}$ & $12.55^{* *}$ & $60.61 * *$ \\
\hline Trans & $107.40^{\mathrm{NS}}$ & $2118.88^{*}$ & $5363.95 * *$ & $2035.56^{*}$ & $377.74^{\mathrm{NS}}$ \\
\hline UPWU & $2674.94 *$ & $4229.72 * *$ & $4108.66 * *$ & $4396.53 * *$ & $5035.99 * *$ \\
\hline GL & $0.21 *$ & $0.11^{*}$ & $0.02^{\mathrm{NS}}$ & $0.11^{*}$ & $0.23^{*}$ \\
\hline GW & $0.18 * *$ & $0.09 * *$ & $0.00^{\mathrm{NS}}$ & $0.10 * *$ & $0.07 * *$ \\
\hline GS & $2.18 * *$ & $2.01 * *$ & $1.62 * *$ & $2.13 * *$ & $4.14 * *$ \\
\hline GT & $0.09^{\mathrm{NS}}$ & $0.04^{\mathrm{NS}}$ & $0.02^{\mathrm{NS}}$ & $0.04^{\mathrm{NS}}$ & $0.04^{\mathrm{NS}}$ \\
\hline GV & $91.90 * *$ & $44.79 * *$ & $6.28^{\mathrm{NS}}$ & $49.90 * *$ & $169.11 * *$ \\
\hline
\end{tabular}

Where, $\mathrm{Df}=$ Degree of Freedom, $*$ = Significant at $5 \%$ level, $* *=$ Significant at $1 \%$ level, NS $=$ Non-significant, FLA $=$ Flag Leaf Area, PH $=$ Plant Height, NOT $=$ Number of Tillers, $\mathrm{PL}=$ Peduncle Length, $\mathrm{SL}=$ Spike Length, NSL $=$ Number of Spikelets, BY $=$ Biological Yield, GY $=$ Grain Yield, GW $=1000$ Grain Weight, WUE $=$ Water Use Efficiency, $\%$ of PY $=$ Percentage of Potential Yield, Trans $=$ Transpiration, UPWU $=$ Unproductive Water Use, GL $=$ Grain Length, GW = Grain Width, GT = Grain Thickness, GS $=$ Grain Size, $\mathrm{GV}=$ Grain Volume

Table 3: Pearson's correlation coefficients among morpho-physiological and grain architecture traits

\begin{tabular}{|c|c|c|c|c|c|c|c|c|c|c|c|c|c|c|c|c|c|}
\hline & FLA & $\mathrm{PH}$ & TILLER & SL & PL & NS & BY & GY & GWT & PY & TRANS & UPWU & WUE & GL & GW & GS & GT \\
\hline PH & $.281^{*}$ & & & & & & & & & & & & & & & & \\
\hline TILLER & $.434 * *$ & $.356^{* * *}$ & & & & & & & & & & & & & & & \\
\hline SL & .241 & $.380^{* * *}$ & .237 & & & & & & & & & & & & & & \\
\hline PL & .138 & $.271^{*}$ & .182 & $.349 * *$ & & & & & & & & & & & & & \\
\hline NS & $.504 * *$ & $.347 * *$ & $.377 * *$ & $.398 * *$ & 189 & & & & & & & & & & & & \\
\hline B_Y & $.270 *$ & .211 & $.327 *$ & $.283 *$ & .137 & .144 & & & & & & & & & & & \\
\hline GY & $.286^{*}$ & $.290 *$ & $.420 * *$ & $.358 * *$ & .124 & $.298 *$ & $.358 * *$ & & & & & & & & & & \\
\hline GWT & $.409 * *$ & .249 & .253 & $.342 * *$ & $.319^{*}$ & .221 & .247 & $.266^{*}$ & & & & & & & & & \\
\hline PY & $.504 * *$ & $.259^{*}$ & $.351 * *$ & .118 & .178 & .164 & $.467 * *$ & .220 & .243 & & & & & & & & \\
\hline TRANS & -.248 & .160 & -.175 & .040 & .168 & -.029 & .095 & -.068 & -.118 & .034 & & & & & & & \\
\hline UPWU & $.510 * *$ & .245 & $.452 * *$ & $.346^{* *}$ & .225 & .243 & $.408 * *$ & $.423 * *$ & $.563 * *$ & $.291 *$ & $-.493 * *$ & & & & & & \\
\hline WUE & $.286^{*}$ & $.290 *$ & $.420 * *$ & $.358 * *$ & .124 & $.298 *$ & $.358 * *$ & $.940 * *$ & $.266^{*}$ & .220 & -.068 & $.423 * *$ & & & & & \\
\hline GL & $.377 * *$ & .146 & .212 & .226 & $.310^{*}$ & $.408 * *$ & $.292^{*}$ & .218 & $.368^{* * *}$ & $.260 *$ & .045 & $.403 * *$ & .218 & & & & \\
\hline GW & $.448 * *$ & $.469 * *$ & $.415^{* *}$ & $.440 * *$ & .252 & $.342 * *$ & .250 & $.395^{* *}$ & $.369 * *$ & $.384 * *$ & -.051 & $.426^{* *}$ & $.395^{* *}$ & $.464 * *$ & & & \\
\hline GS & $.363 * *$ & .193 & .208 & $.271 *$ & .211 & $.313 *$ & .214 & $.270^{*}$ & $.349 * *$ & $.273 *$ & -.008 & $.409 * *$ & $.270 *$ & $.740 * *$ & $.816^{* * *}$ & & \\
\hline GT & $.271 *$ & $.348^{* *}$ & $.320 *$ & $.375^{* * *}$ & $.341 * *$ & $.265^{*}$ & .253 & $.262 *$ & $.363 * *$ & $.300^{*}$ & .050 & $.326^{*}$ & $.262 *$ & $.365^{* *}$ & $.553 * *$ & $.434 * *$ & \\
\hline GV & $.374 * *$ & $.258^{*}$ & $.284^{*}$ & $.327 *$ & $.293^{*}$ & $.325^{*}$ & .244 & $.303^{*}$ & $.420 * *$ & $.292^{*}$ & -.030 & $.450 * *$ & $.303^{*}$ & $.692 * *$ & $.822 * *$ & $.912 * *$ & $.726 * *$ \\
\hline
\end{tabular}

*. Correlation is significant at the 0.05 level, **. Correlation is significant at the 0.01 level

FLA = Flag Leaf Area, PH = Plant Height, TILLER = Number of Tillers, SL $=$ Spike Length, PL $=$ Peduncle Length, NS $=$ Number of Spikelets, BY $=$ Biological Yield, GY = Grain Yield, GWT $=1000$ Grain Weight, PY $=\%$ of Potential Yield, TRANS $=$ Transpiration, UPWU $=$ Unproductive Water Use, WUE $=$ Water Use Efficiency, GL $=$ Grain Length, GW = Grain Width, GS = Grain Size, GT = Grain Thickness, GV = Grain Volume

PCs were extracted having a cumulative variance of $78.87 \%$ (Table 4). Similarly, Beheshtizadeh et al. (2013) indicated four significant components accounting for almost $76 \%$ of the total diversity between the traits in wheat varieties. The first principal component showed the highest contribution (35.48\%) towards the total variation. The PCA loadings indicated that grain width contributed maximum to the variation followed by unproductive water use, grain area size and grain volume. The contribution of all the traits was positive except transpiration which contributed negatively (Fig. 2). The second PC contributed $10.54 \%$ to the total variation. The maximum positive contribution in $\mathrm{PC} 2$ was observed for grain area followed by grain length and grain volume. A negative contribution was found for number of tillers per plant, grain yield, and water use efficiency (Fig.
3). The maximum positive contribution of the traits to $\mathrm{PC} 3$ was found in transpiration followed by plant height (Fig. 4). The maximum positive contribution in PC4 was exhibited by percentage of potential yield followed by flag leaf area and biological yield (Fig. 5). While PC5 contributed $6.4 \%$ to the total diversity having highest positive contribution of spike length and peduncle length followed by plant height and 1000 grain weight. The maximum positive contribution to PC6 was contributed by biological yield followed by peduncle length, 1000 grain weight and unproductive water use. The last significant PC contributed $4.63 \%$ to the total variation with positive contribution of characters like grain length, number of spikelets spike ${ }^{-1}$ while negative contribution was found in grain thickness and plant height. Biplot of the first two PCs 
Table 4: Principal component analysis for morpho-physiological and grain architecture traits in 60 spring wheat varieties

\begin{tabular}{llll}
\hline PC & Eigen value & Variance $(\%)$ & Cumulative variance \\
\hline 1 & 6.39 & 35.48 & 35.48 \\
2 & 1.90 & 10.54 & 46.02 \\
3 & 1.50 & 08.31 & 54.33 \\
4 & 1.36 & 07.57 & 61.09 \\
5 & 1.17 & 06.48 & 68.38 \\
6 & 1.05 & 05.86 & 74.24 \\
7 & 0.83 & 04.63 & 78.87 \\
\multicolumn{2}{l}{ Joliffe's cut off value $=0.75$}
\end{tabular}

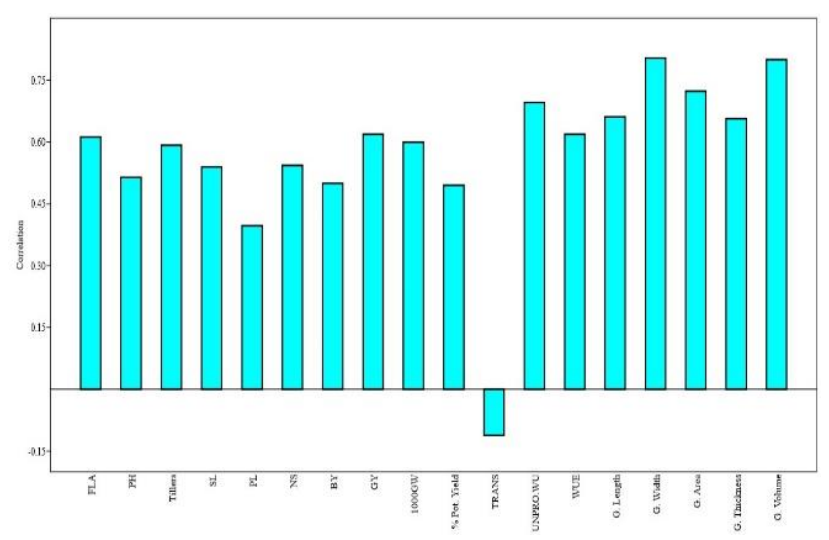

Fig. 2: Loadings for PC 1 obtained from morpho-physiological and grain architecture traits in 60 varieties of wheat

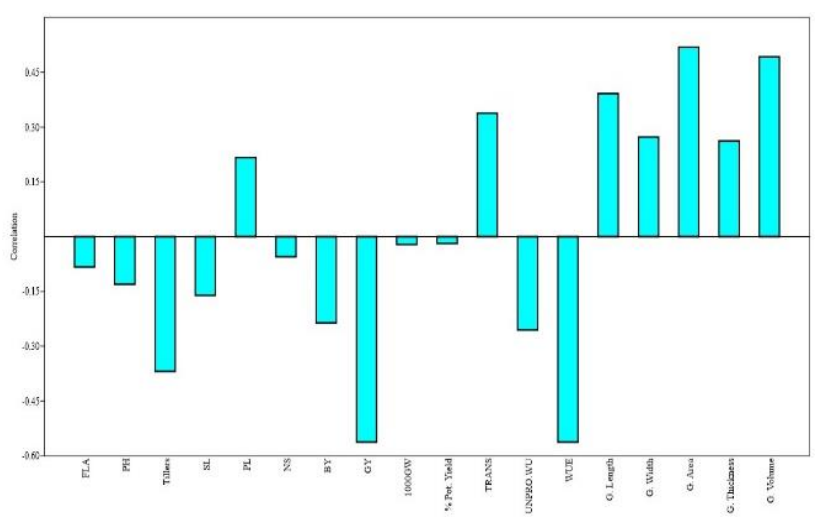

Fig. 3: Loadings for PC 2 obtained from morpho-physiological and grain architecture traits in 60 varieties of wheat

revealed that WUE, grain yield, number of tillers, grain area size and grain volume had maximum contribution towards the total variance (Fig. 6). The varieties Manthar-03, Kaghan-93, Pirsabak-2013, KT-2000, NIA-Amber, Gomal08, Janbaz, Kiran-85, SH-2002, Bahawalpur-97, Nasir-2K, Khyber-81, and Dharabi-2011 were outliers showing diversity. The varieties Pak-81, Ufaq-2002, Millet-2011, Takbeer and Fakhar-e-Sarhad were the high yielding so lie very close to the grain yield vector. While varieties like Manthar-03, Pirsabak-2013 and Kaghan-93 showed the highest while BWL-97, Gomal-08 and Nasir-2K showed the lowest values for grain morphology, grain yield and water use efficiency.

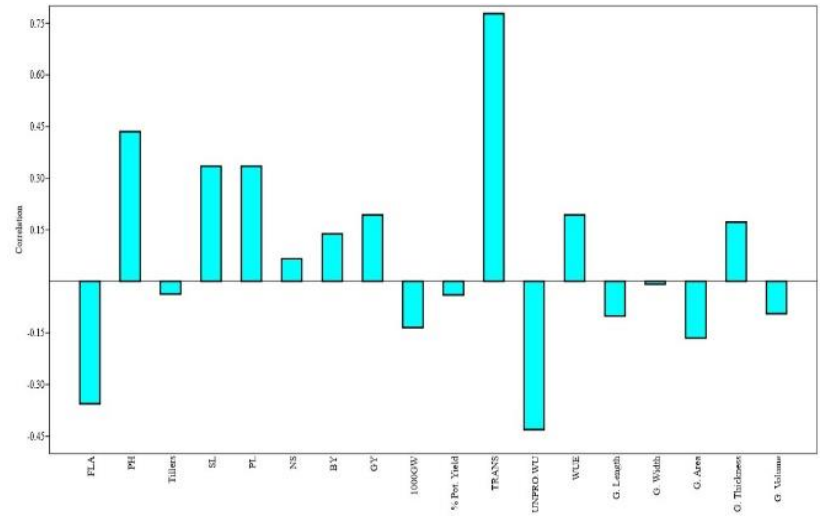

Fig. 4: Loadings for PC 3 obtained from morpho-physiological and grain architecture traits in 60 varieties of wheat

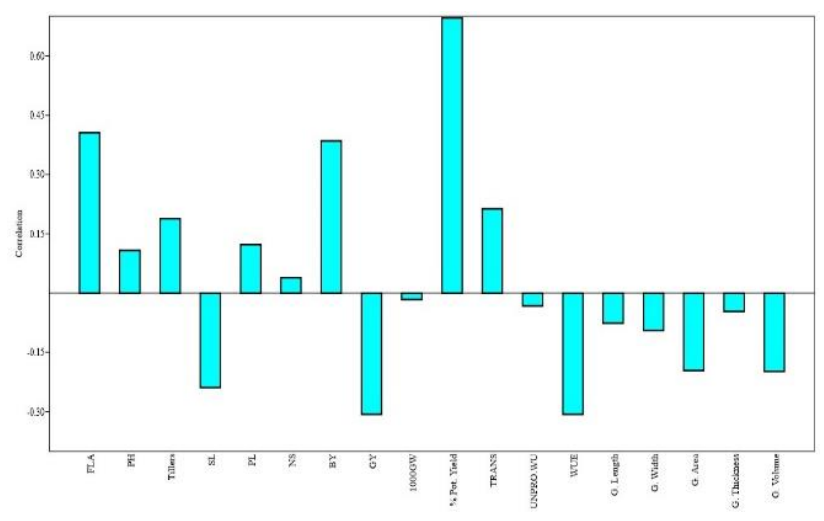

Fig. 5: Loadings for PC 4 obtained from morpho-physiological and grain architecture traits in 60 varieties of wheat

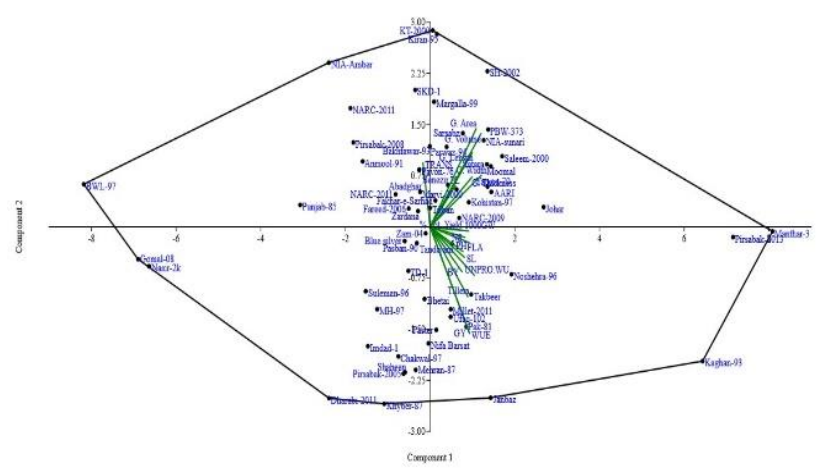

Fig. 6: Biplot diagram obtained from morpho-physiological and grain architecture traits in 60 varieties of wheat

\section{Cluster analysis}

The dendrogram based on various morpho-physiological traits of wheat varieties indicated seven logical clusters based on similarities and differences (Fig. 7). The 06 varieties included in cluster 1 were high in grain morphology, grain yield, and water use efficiency. While the cluster 2 included 09 varieties, moderate in grain yield 


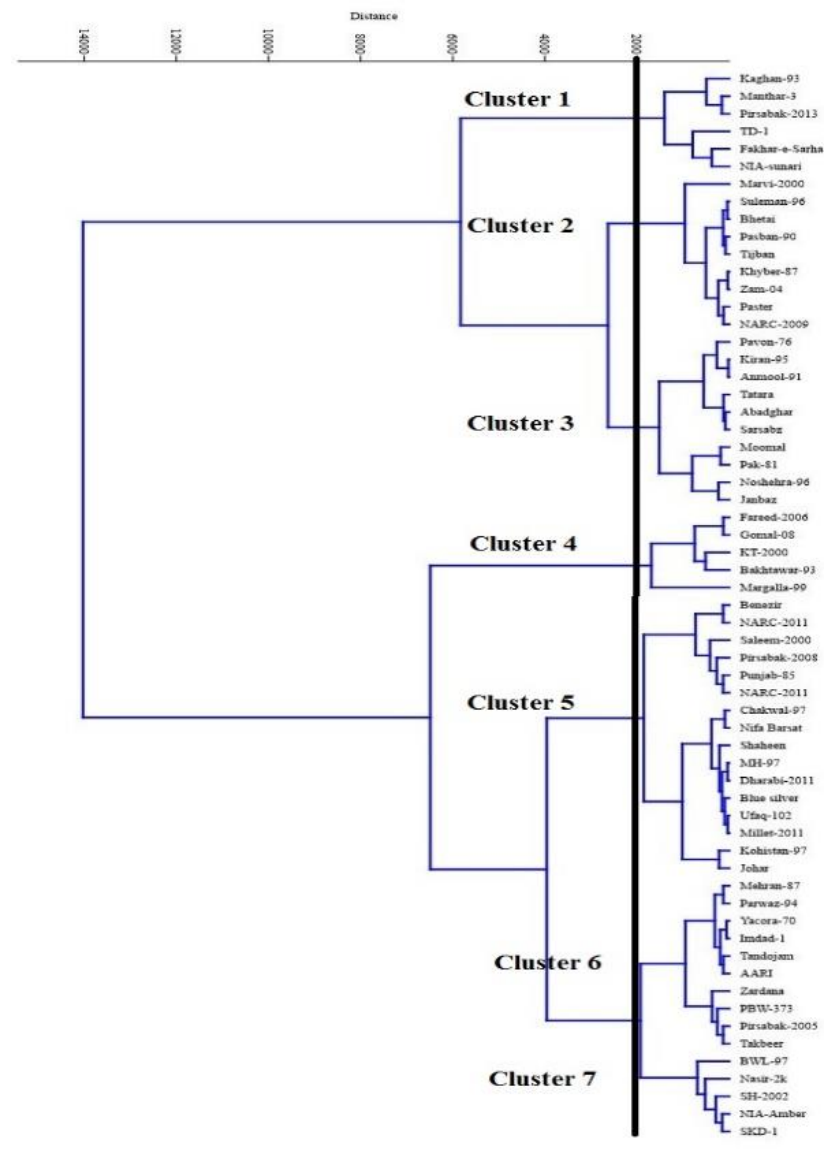

Fig. 7: Dendrogram of 60 wheat varieties based on water use efficiency, grain morphology, grain yield and yield related traits

and water use efficiency and low in grain morphology. Similarly, the cluster 03 contained 10 varieties which were moderate to low in grain yield, water use efficiency and high in grain morphology traits. The cluster 04 comprised of 05 varieties, low in grain yield, water use efficiency and low to moderate in grain morphology. The cluster 05 contained 16 varieties which were moderate in grain yield, water use efficiency and grain morphology traits. However, the cluster 06 consisted of 10 varieties characterized by moderate in grain yield, water use efficiency and moderate to high in grain morphology. The cluster 07 contained 05 varieties which were lowest in grain yield, water use efficiency and grain morphology traits.

\section{Discussion}

The use of less water to achieve higher yield is a major objective of the modern agriculture (Araus 2004). As world cereal demand is increasing, producing more grains per unit of water during the crop cycle through higher WUE may have strong impact at local and regional level (Tambussi et al. 2007). The increase in individual grain weight and size has the potential to improve wheat yield (Molero et al.
2019). Genetic manipulation of grain morphology through selection can lead to increase in yield potential (Calderini et al. 2021). Manual measurement methods of grain parameters have some limitations, like limited data and lowquality measurements. Therefore, high-throughput grain phenotyping method is needed to validate the genetic analysis and selection for seed shape in plant breeding (Williams et al. 2013).

Analysis of variance (ANOVA) is a statistical test for detecting differences in group means when there is one parametric dependent variable and one or more independent variables (Sawyer 2009). To test the significant difference among the varieties for various parameters, the ANOVA was computed. ANOVA and descriptive statistics represented that the varieties have higher variability for the target traits, like water use efficiency and grain morphology to initiate a breeding program (Table 2). Awan et al. (2015) also indicated variability in 176 wheat varieties to initiate a breeding program. Correlation coefficient analysis assesses the joint association between varieties of plant traits. It also finds out the component traits on which we can base selection for genetic enhancement in yield (Barman et al. 2020). To find the degree and direction of association of yield with the traits contributing to yield and interrelationship among them, analysis of correlation coefficient was executed. The correlation coefficient showed a positive relationship of WUE with grain morphology. Hasan et al. (2011) indicated a positive relation among WUE and wheat grain. In addition, positive correlations were observed among 1000 grain weight, grain yield, grain morphology traits and water use efficiency. The traits like 1000 grain weight, WUE and grain architectural traits are suggested as the simplest indirect way to improve grain yield. Similarly, Kanwal et al. (2019) observed significant positive correlation of grain size for grain yield, days to anthesis, days to maturity, spikelets spike $^{-1}$, plant height and flag leaf area. While, Khokhar et al. (2021) indicated negative association among plant height and grain yield per plant.

Analysis of crop genetic diversity and structure provides valuable information needed to broaden the narrow genetic base as well as to devise the breeding and conservation strategies of crops (El-Esawi et al. 2018). Cluster analysis and PCA are effective bio-statistical tools for the identification of genetic diversity, selection of parents, center of origin and diversity, tracking evolutionary pathway of the crops, and to study interaction with the environments (Khodadadi et al. 2011). Principal component analysis can transform several possibly correlated variables into a smaller number of variables called principal components. It has been argued that principal component analysis should be conducted before cluster analysis (Mujaju and Chakuya 2008). Several authors have suggested the use of cluster and principal component analyses to study the genetic diversity and relationships of wheat genotypes (Lysenko 2011; Beheshtizadeh et al. 2013; Adilova et al. 2020; Tariq et al. 2020). The PCA indicated 
seven significant PCs. In PC1, grain width contributed maximum to the variation followed by unproductive water use, grain area size and grain volume (Fig. 2). The grain width, unproductive water use, grain area size, and grain volume showed maximum load for this PC indicating that these were the most variable traits. However, Tańska et al. (2018) pointed out that the seed dimensions and shape were constant among the cultivars with highest variation shown by grain thickness and grain volume. The highest values for grain width, unproductive water use, grain size and grain volume indicated a positive correlation among these traits. Yoshioka et al. (2019) also reported a positive correlation among grain morphology traits and concluded that bread wheat had the largest diversity in grain morphology. The PC1 also indicated a negative correlation between grain morphology traits and transpiration, endorsing the results obtained from Pearson's correlation showing negative but non-significant relationship. The PC2 indicated a negative relationship among the grain characteristics like grain area, grain length, grain volume and morpho-physiological traits like number of tillers plant ${ }^{-1}$, grain yield, and water use efficiency (Fig. 3). Gegas et al. (2010) reported the traits like grain shape and size is under the influence of distinct genetic components in wheat. Yoshioka et al. (2019) speculated that grain characters are the outcome of epistatic interactions of multiple genetic factors. Rest of the significant PCs i.e., from PC3 to PC7 contributed $32.85 \%$ to the total diversity. The relative contribution to total diversity decreased with the succeeding PCs indicating decreased contribution of traits residing in those PCs to total diversity. The loadings from PCA describe the strength of the relationship between the parameter and the component; these are linear weights that account for the full variance of the parameters (Byrne 2005). The traits with highest load in the initial PCs are more variable than those found in later PCs. The highest positive load of the traits to PC3 was observed in transpiration followed by plant height (Fig. 4). While in PC4 maximum positive load was exerted by percentage of potential yield followed by flag leaf area and biological yield (Fig. 5). Awan et al. (2015) reported grain yield/plant was closely related to flag leaf area.

The biplot was introduced by Gabriel in 1971. It is a plot of two kinds of information displayed together (Gower et al. 2015). This paper deals with biplot obtained from quantitative data generated by the first two principal components. The biplot revealed the interaction of traits and varieties (Fig. 6). It was observed that WUE, grain yield, number of tillers, grain area size and grain volume had maximum contribution towards the total variance, as indicated by the longest vector length. Similarly, the varieties lying near to and in the same quadrate of their respective vectors showed higher values for the development of those traits. The vectors for spike length, peduncle length lie very close to the origin hence their role could not be predicted. The varieties showed variation, as they scattered around the quadrates of biplot. The varieties
Manthar-03, Kaghan-93, Pirsabak-2013, KT-2000, NIAAmber, Gomal-08, Janbaz, Kiran-85, SH-2002, Bahawalpur-97, Nasir-2K, Khyber-81, and Darabi-2011 were outliers and considered most diverse. The varieties found in the same quadrate and lying near to the grain yield and grain quality vectors were found high yielding with better grain quality and vice versa. The varieties Pak-81, Ufaq-2002, Millet-2011, Takbeer and Fakhar-e-Sarhad showed the highest grain yield as they lie very close to the grain yield vector. The varieties showing the lowest yield were found furthest from vector and in the opposite quadrate. The varieties like Manthar-03, Pirsabak-2013 and Kaghan-93 showed the highest values while BWL-97, Gomal-08 and Nasir-2K showed the lowest values for grain morphology, grain yield and water use efficiency. These varieties may be selected for further hybridization and estimation of genetic components. Analysis of genetic diversity and population structure is an essential step in their conservation, utilization and breeding (Iqbal et al. 2018; Holasou et al. 2019). The genetic variability based on morphological characters especially those of economic interest could also be used to select appropriate materials in breeding programs for crop improvement (Farooq et al. 2014; Xhulaj et al. 2019; Ul-Allah et al. 2019). The cluster analysis indicated 07 clades based on morpho-physiological traits in 60 wheat varieties while Drikvand et al. (2013) grouped 92 wheat cultivars into six clusters.

Based on cluster diagram (Fig. 7) two sets of varieties were identified i.e., those showing highest and lowest performance for target traits like grain yield, water use efficiency and grain morphology traits. Therefore, the varieties grouped in clusters 01,04 and 07 may be selected for further studies. The varieties included in the highperformance set of target traits were Kaghan-93, Manthar03 and Pirsabak-2013 while those of low performance set of target traits were Bahawalpur-97, Nasir-2K and Gomal-08. These results confirmed the observations depicted in the biplot diagram. These varieties can be exploited as parents for transgressive breeding and could be used to stack favorable alleles into elite breeding lines through convergent crossing.

\section{Conclusion}

The germplasm showed high variation for grain morphology, WUE and morpho-physiological traits. This variation was quite encouraging to initiate a breeding program targeting to improve these traits. The traits related to grain morphology could be recommended for the indirect selection of grain yield and WUE. Cluster analysis grouped varieties into seven clusters of high, medium and low performance for target traits. This classification may help in the selection of high and low performing varieties and can be used as parents in hybridization program. The varieties like Kaghan-93, Manthar-03 and Pirsabak-2013 were recommended as highest performing varieties, while 
Bahawarpur-97, Nasir-2K, and Gomal-08 were lowest performing varieties for the grain yield, grain morphology traits and water use efficiency. These varieties can be exploited as parents to produce variability in succeeding generations and to combine the alleles from parents into a single progeny through convergent crossing.

\section{Acknowledgements}

Authors are thankful to Wheat Program, National Agriculture Research Center (NARC) Islamabad, Pakistan for the provision of authenticated seed material of wheat varieties. The research work was funded by the Department of Plant Breeding and Molecular Genetics, University of Poonch Rawalakot.

\section{Author Contributions}

Shafiq-Ur-Rehman executed the experiment and wrote the initial draft of the manuscript as a Ph.D. scholar. Sardar Ali Khan finalized the draft of the manuscript. Shahid Iqbal Awan planned the experiment and guided the scholar. Muhammad Ilyas contributed to the analysis of data.

\section{Conflict of Interest}

The authors declare that they have no conflict of interest.

\section{Data Availability}

Data are available from the authors on request.

\section{Ethics Approval}

The research work was conducted after approval from the Human \& Animal Ethics Committee of University and no humans and animals were investigated.

\section{References}

Adilova SS, DE Qulmamatova, SK Baboev, TA Bozorov, AI Morgunov (2020). Multivariate cluster and principal component analyses of selected yield traits in Uzbek bread wheat cultivars. Amer J Plant Sci 11:903-912

Ahmad MQ, M Hassan, A Qayyum, MA Saleem, W Malik, E Noor, S UlAllah (2019). Characterization of synthetic wheatgerm plasm using morphological and molecular markers. Intl J Agric Biol 22:131-138

Ali A, Z Ullah, N Alam, SMS Naqvi, M Jamil, H Bux, H Sher (2020). Genetic analysis of wheat grains using digital imaging and their relationship to enhance grain weight. Sci Agric 77; Article e20190069

Araus JL (2004). The problem of sustainable water use in the Mediterranean and research requirements for agriculture. Ann Appl Biol 144:259-272

Awan SI, SD Ahmad, MA Ali, MS Ahmed, A Rao (2015). Use of multivariate analysis in determining characteristics for grain yield selection in wheat. Sarhad J Agric 31:139-150

Barman M, VK Choudhary, SK Singh, R Parveen, AK Gowda (2020). Correlation and path coefficient analysis in bread wheat (Triticum aestivum L.) genotypes for morphophysiological traits along with grain Fe and Zn content. Curr J Appl Sci Technol 39:130-140
Beheshtizadeh H, A Rezaie, A Gandi (2013). Principal component analysis and determination of the selection criteria in bread wheat (Triticum aestivum L.) genotypes. Intl J Agric Crop Sci 5:2024-2027

Beral A, R Rincent, JL Gouis, C Girousse, V Allard (2020). Wheat individual grain-size variance originates from crop development and from specific genetic determinism. PLoS One 15; Article e0230689

Byrne BM (2005). Factor analytic models: Viewing the structure of an assessment instrument from three perspectives. J Person Assessm $85: 17-32$

Calderini DF, FM Castillo, A Arenas-M, G Molero, MP Reynolds, M Craze, S Bowden, MJ Milner, EJ Wallington, A Dowle, LD Gomez, SJ McQueen-Mason (2021). Overcoming the trade-off between grain weight and number in wheat by the ectopic expression of expansion in developing seeds leads to increased yield potential. New Phytol 230:629-640

Clarke MP, MJ Gooding, SA Jones (2004). The effects of irrigation, nitrogen fertilizer and grain size on Hagberg falling number, specific weight and black point of winter wheat. J Sci Food Agric $84: 227-236$

Drikvand R, MR Bihamta, G Najafian, A Ebrahimi (2013). Investigation of genetic diversity among bread wheat cultivars (Triticum aestivum $\mathrm{L}$.) using SSR markers. J Agric Sci 5:122-129

El-Esawi MA, J Witczak, AE Abomohra, HM Ali, MS Elshikh, M Ahmad (2018). Analysis of the genetic diversity and population structure of Austrian and Belgian wheat germplasm within a regional context based on DArT Markers. Genes 9; Article 47

Evers AD, RI Cox, MZS Ullah, RP Withey (1990). Predicting milling extraction rate by image analysis of wheat grains. Asp Appl Biol $25: 417-426$

Farooq M, M Hussain, KHM Siddique (2014). Drought stress in wheat during flowering and grain filling periods. Crit Rev Plant Sci 33:331-349

French RJ, JE Schultz (1984). Water use efficiency of wheat in a Mediterranean-type environment: 1 . The relationship between yield, water use and climate. Aust J Agric Res 35:743-764

Gegas VC, A Nazari, S Griffiths, J Simmonds, L Fish, S Orford, JW Snape (2010). A genetic framework for grain size and shape variation in wheat. Plant Cell 22:1046-1056

Gower JC, NJL Roux, S Gardner-Lubbe (2015). Biplots: Quantitative Data. Wiley Interdiscipl Rev Comput Stat 7:42-62

Hair JF, WC Black, BJ Babin, RE Anderson, RL Tatham (2006). Multivariate Data Analysis, $6^{\text {th }}$ edn. Pearson Education Inc and Dorling Kindersley Publishing Inc., London, UK

Hammer O, DAT Harper, PD Ryan (2001). PAST: Paleantological statistics software package for education and data analysis. Palaeontol Electr 4:1-9

Hasan AK, J Herrera, C Lizana, DF Calderini (2011). Carpel weight, grain length and stabilized grain water content are physiological drivers of grain weight determination of wheat. Field Crop Res 123:241-247

Holasou A, H Rahmati, F Rahmani (2019). Elucidate genetic diversity and population structure of bread wheat (Triticum aestivum L.) cultivars using IRAP and REMAP Markers. J Crop Sci Biotechnol 22:139-151

Hunt JR, JA Kirkegaard (2013). A guide to consistent and meaningful benchmarking of yield and reporting of water-use efficiency. CSIRO, Canberra, ACT. Available at: https://publications.csiro.au/rpr/download?pid=csiro:EP156113\& dsid=DS2 (Accessed: 21 September 2020)

Iqbal M, S Ul-Allah, M Naeem, M Hussain, M Ijaz, A Wasaya, MQ Ahmad (2018). Reproductive development and seed cotton yield of Gossypium hirsutum L. affected by genotype and planting time. Intl J Agric Biol 20:1590-1596

Kanwal A, Z Ali, R Shahzad, M Makhdoom, I Ghafoor, S Saleem, A Bakhsh, M Zulkiffal, N Parveen, Aziz-ur-Rehman, J Ahmad (2019). Genetic diversity for grain size and its association with yield components in bread wheat. Intl J Biosci 14:112-122

Khodadadi M, MH Fotokian, M Miransari (2011). Genetic diversity of wheat (Triticum aestivum L.) genotypes based on cluster and principal component analyses for breeding strategies. Aust J Crop Sci $5: 17-24$ 
Khokhar MI, M Hussain, M Zulkiffal, N Ahmad, W Sabar (2021). Correlation and path analysis for yield and yield contributing characters in wheat (Triticum aestivum L.). Intl J Agric Sci 11:1-3

Kumar B, GM Lal, Ruchi, A Upadhyay (2009). Genetic variability, diversity and association of quantitative traits with grain yield in bread wheat (Triticum aestivum L.). Asian J Agric Sci 1:4-6

Lysenko AA (2011). Comparative productivity of pea varieties of various morphotypes and the creation of a new selection material on their basis, p: 23. Zernograd

Marshall DR, DJ Mares, HJ Moss, FW Ellison (1986). Effects of grain shape and size on milling yields in wheat. Aust J Agric Res 37:331-342

Molero G, R Joynson, FJ Pinera-Chavez, LJ Gardiner, C Rivera-Amado, A Hall, MP Reynolds (2019). Elucidating the genetic basis of biomass accumulation and radiation use efficiency in spring wheat and its role in yield potential. Plant Biotechnol J 17:1276-1288

Mujaju C, E Chakuya (2008). Morphological variation of sorghum landrace accessions on-farm in semi-arid areas of Zimbabwe. Intl $J$ Bot 4:376-382

Nuttall JG, GJ O’Leary, JF Panozzo, CK Walker, KM Barlow, GJ Fitzgerald (2017). Models of grain quality in wheat-A review. Field Crop Res 202:136-145

Rasheed A, X Xia, F Ogbonnaya, T Mahmood, Z Zhang, A Mujeeb-Kazi, Z $\mathrm{He}$ (2014). Genome-wide association for grain morphology in synthetic hexaploid wheats using digital imaging analysis. BMC Plant Biol 14; Article 128

Sawyer SF (2009). Analysis of Variance: The Fundamental Concepts. $J$ Man Manip Ther 17:27-38
Snedecor GW (1956). Statistical Methods, $5^{\text {th }}$ edn, Iowa State University Press, Ames, Iowa, USA

Tambussi EA, J Bort, JL Araus (2007) Water use efficiency in $\mathrm{C}_{3}$ cereals under Mediterranean conditions: a review of physiological aspects. Ann Appl Biol 150:307-321

Tańska M, J Buczek, W Jarecki, A Wasilewska, I Konopka (2018). Grain morphology, texture and colour-related compounds of bread wheat cultivars in relation to cultivation regimes and growing location. Zemdirbyste-Agriculture 105:105-112

Tariq H, SI Awan, SM Sabir, M Ilyas (2020). Species of wheat: hexaploidtetraploid landraces and wild, revealed diversity for antioxidants and total phenolics. Philipp Agric Sci 103:29-37

Ul-Allah S, S Ahmad, M Iqbal, M Naeem, M Ijaz, MQ Ahmad, Z Hassan, HG Nabi (2019). Creation of new genetic diversity in cotton germplasm through chemically induced mutation. Intl J Agric Biol 22:51-56

Williams K, J Munkvold, M Sorrells (2013). Comparison of digital image analysis using elliptic fourier descriptors and major dimensions to phenotype seed shape in hexaploid wheat (Triticum aestivum L.). Euphytica 190:99-116

Xhulaj D, F Elezi, V Hobdari (2019). Interrelationship among traits and morphological diversity of wheat (Triticum aestivum L.) accessions in base collection of Plant Genetic Resources. Acta Agric Sloven 113:163-179

Yoshioka M, T Shotaro, N Miyuki, L Jianjia, M Nobuyuki, N Shuhei (2019). Genetic dissection of grain morphology in hexaploid wheat by analysis of the NBRP-wheat core collection. Genes Genet Syst 94:35-49 